\title{
Knowledge Levels of Paramedic Program Senior Year Students on Frequently Used Drugs and Interventional Procedures: A Comparative Study
}

\author{
(1) Tuğba Gültekin, (1) Sinan Yenal
}

First and Emergency Aid Program, Health Services Vocational School, Dokuz Eylül University, İzmir, Turkey

\begin{abstract}
Aim: This study aimed to determine and compare the knowledge level of senior year students studying the paramedic program at Dokuz Eylül (DEU), Ege (EU) and İzmir Katip Çelebi (IKÇU) universities on frequently used drugs and interventional procedures.

Materials and Methods: This descriptive study was conducted with 167 students in first and emergency aid programs of three universities with DEU, EU and IKÇU in between March 30, 2019 and December 30, 2019. Descriptive findings were presented as percentage, mean, standard deviation, and median.

Results: Of the participants, $52.1 \%$ were females and the remaining $47.9 \%$ were males. The most common issues for which the paramedic students felt incompetent were drug doses (58.6\%) and interventional procedure complications (60.4\%). The mean total score of the knowledge level of the paramedic students on drugs and administration methods was 54.724. The total mean total score of the knowledge level of interventional procedures in paramedic students was 65.653. There was no difference in the knowledge level on drugs and administration methods in terms of the different universities $(p=0.470)$. However, a significant difference was found in the knowledge level on interventional procedures between the students studying at different universities $(p=0.002)$. Advanced analysis revealed that the difference was due to iKÇU students $(p<0.806)(p<0.004$ for DEU and EU).

Conclusion: It was determined that paramedic students had low knowledge level on drug usage and interventional procedures. Therefore, the training of paramedics who will work in pre-hospital emergency health service needs to be standardized while considering the deficiencies and including updates.
\end{abstract}

Keywords: Paramedic, drug applications, intervention skills, knowledge level, public health

\section{Introduction}

Pre-hospital emergency health services cover the emergency care services provided by specially trained and well-equipped teams given at the scene and/or during transportation until the arrival of patients or injured persons to the hospital, and emergency care services provided in health institutions and organizations (1).

This specially equipped personnel working in the harsh conditions at pre-hospital emergency health services and carrying the roles and responsibilities that may be required in the field began working in ambulances in the 1950s especially in the North American countries. On the other side in Turkey, staff training specific to the pre-hospital field began in the early 1990s $(2,3)$.
The development of emergency medicine in Turkey began in 1990 in Dokuz Eylül University (DEU) when an American emergency medicine specialist Dr. John Fowler was invited to Turkey by DEU and began working at the Emergency Room of DEU Hospital. "Emergency Medicine" was recognized as a separate specialty in 1993 by Dr. John Fowler's active efforts and two emergency medicine departments, DEU Emergency Medicine Department and Firat Universty Emergency Medicine Department were founded in the same year $(4,5)$.

Within the scope of "Emergency and Rescue Services Project" initiated by the Ministry of Health in 1994, fully equipped ambulances were purchased, radio network was renewed, a 
telephone exchange was established, and new emergency aid stations were constructed. In those years, nurses started to work for the first time in ambulances next to physicians and drivers, and the first training on emergency health services was carried out (6).

Emergency Care Technician program, established for the first time in Turkey at DEU in the 1993-1994 academic year as part of the Health Services Vocational School with the Canada-Cambrian College collaboration became one of the first and most important steps taken in the field of pre-hospital emergency care in Turkey. The purpose of this program was to educate and train the personnel who can provide pre-hospital emergency care needed by the patients and the injured at a professional level $(4,5)$.

In 2004, a new era began in Turkey when paramedics started to work in 112 ambulances. Their roles and responsibilities were determined by relevant regulations. The Regulation on Emergency Health Services was published in the Official Newspaper in 2007. In 2009, Communiqué on Working Procedures and Principles of Ambulance and Emergency Care Technicians and Emergency Medical Technicians was published in the Official Gazette, and the roles and responsibilities of the paramedics were defined in this communiqué. The Paramedic Training Coordination Board continues its meetings in parallel with scientific developments, especially medicine, and developments in the roles and responsibilities of professional members $(7,8)$.

The most important task, power, and responsibilities of paramedics are to use emergency medications (atropine, adrenaline, amiodarone, metoprolol, midazolam, diltiazem, calcium, etc.) which are accepted in the pre-hospital period until patients reach the hospital and perform vital interventional procedures (defibrillation, intraosseous, laryngeal mask airway, capnometry, etc.).

The number of programs was less than 20 in the early 2000s. This number reached approximately 150 in 2016 and occupational members without adequate occupational competence graduating from these programs opened without concern for qualified educators or occupational training infrastructure led to a serious discussion of occupational roles and responsibilities $(2,9)$.

After long term efforts in Turkey on standardization activities, a standard curriculum has been prepared for paramedic training. However, today's issue is not that these curricula have been standardized, but rather these standardized curricula prepared after long and arduous efforts cannot be implemented due to lack of infrastructure and a large number of students $(2,10)$.
The paramedic profession is a different occupational group compared to others, therefore the methods to be applied in training and education also differ. One of the most important problems for today is that the instructors working in vocational education, who come from different occupational groups, do not have the sufficient knowledge and skills required by the profession.

In addition, student quotas exceeding capacity affect the quality of education and rapidly increase the number of graduates, causing employment problems. The aim of the paramedic programs today should be to train qualified paramedics who can fulfill the roles and responsibilities of the profession with the appropriate number of students.

We believe that determining the knowledge levels of paramedic program (first and emergency aid technicians) senior year students on commonly used drugs and interventional procedures in this study will contribute to the literature and all stakeholders for reviewing and restructuring pre-graduation training.

\section{Purpose of the Study}

Study was planned to determine and compare the knowledge level of senior year students studying in the paramedic programs at DEU, EU, IKÇU universities, about frequently used drugs and interventional procedures.

\section{Materials and Methods}

\section{Study Design}

This study was designed as a comparative study.

\section{Place and Time of Study}

This study was carried out in DEU, EU and IKÇU Vocational School of Health Services between March 30, 2019, and December 30, 2019.

\section{Population and Sample of Study}

The population of the study consisted of 200 senior students studying in First and Emergency Aid programs in DEU (60 students), EU (70 students) and IKÇU (70 students) Vocational School of Health Services in the 2018-2019 spring semester.

Since the information related to the research questions was homogeneous with respect to the population, the simple random sampling method was used and the entire population was reached without any sampling. The study was conducted with 167 students who accepted to participate in the study.

Although there are limited studies on this subject, the frequency of inadequate knowledge level of paramedics on drug and drug applications is reported to be $48 \%$ in another study (11). 
According to these data, the minimum number of paramedic students to be included in the study within 95\% confidence interval and $\pm 5 \%$ frequency limits were calculated as 65 (12-14). Two hundred senior paramedic students between the ages of 1827 who are enrolled in the vocational schools were planned to be included in the study.

\section{Research Summary}

Data collection was performed in March-April 2019, in the classroom, during extracurricular hours. Students were given 2025 minutes to complete the measurement tools and then the forms were collected by the researcher.

\section{Data Collection (Measurement) Tool}

The measurement tool developed by Haytaç (11) in 2017 to determine the knowledge level of students on commonly used drugs and interventional procedures in the pre-hospital period was used in this study (11). In the first part of this measurement tool, there are a total of eight descriptive questions that identify the person. In the second part of the measurement tool, there are 32 statements about intravenous drugs commonly used in the emergency department and 112 ambulance. In the third part, there are 28 statements about interventional and other devices commonly used in an emergency room and 112 ambulances. As there are limited studied on this subject, the validity and reliability study of the form has not been conducted by the researchers. The permission for the use of the form was obtained from the responsible researcher via e-mail.

\section{Statistical Analysis}

SPSS (Statistical Package for Social Sciences) version 25.0 was used for statistical analysis of the obtained data. Descriptive findings were evaluated as percentage, mean, standard deviation, and median (12). Continuous numerical variables were analyzed by the Kolmogorov-Smirnov method and it was found that the variables were not normally distributed $(p<0.05)$. Therefore, the One-way ANOVA test method was preferred for comparing one dependent and one independent group. PostHoc ANOVA test was used as an advanced analysis method in multiple comparisons which were found to be significant. In the entire study, the type-I error rate was taken as $5 \%$ and $p<0.05$ was considered statistically significant.

\section{Ethics Committee Approval and Informed Consent}

Written consent for data collection was obtained from the Research Ethics Committee of DEU and the institutions where the study was carried out. Paramedic students were informed about the study and verbal consent was obtained from those who accepted to participate in the study.

"TREND Statement Checklist" guide was used in the preparation of the article.

\section{Results}

The study was conducted with 167 senior year paramedic students. Eighty-seven (52.1\%) of the participants were female and $80(47.9 \%)$ were male. $89.2 \%$ of the participants were in the 19 -21 age range, $9.0 \%$ in the $22-24$ age range, and $3.0 \%$ in the 25-27 age range. The demographic data of the participants are given in Table 1.

\begin{tabular}{|c|c|c|c|}
\hline \multicolumn{2}{|c|}{$\begin{array}{l}\text { Socio-demographic } \\
\text { characteristics }\end{array}$} & \multirow{2}{*}{\begin{tabular}{|l|}
$\mathbf{n}$ \\
149 \\
\end{tabular}} & \multirow{2}{*}{\begin{tabular}{|l|}
$\%$ \\
89.2 \\
\end{tabular}} \\
\hline \multirow{3}{*}{ Age } & 19-21 years & & \\
\hline & 22-24 years & 15 & 9.0 \\
\hline & 25-27 years & 3 & 1.8 \\
\hline \multirow[t]{2}{*}{ Gender } & Male & 80 & 47.9 \\
\hline & Female & 87 & 52.1 \\
\hline \multicolumn{2}{|l|}{ Total } & 167 & 100 \\
\hline \multicolumn{4}{|c|}{$\mathrm{n}$ : Number } \\
\hline
\end{tabular}

Table 2 shows the distribution of paramedics' answers to the questions asked to investigate their competence perceptions about drug and intervention procedures.

When paramedic students were asked "Do you think that your knowledge level on drugs and drug applications is sufficient?", 47.3\% replied "yes", $11.9 \%$ replied "no", and 40.8\% replied "undecided". When paramedic students were asked "Do you think that your knowledge level on interventional procedures is sufficient?", $77.8 \%$ replied "yes", $4.7 \%$ replied "no", and 17.3\% replied "undecided". When paramedic students were asked "Do you think you should be further trained on drugs and interventional procedures?", 67\% replied "yes", 17.9\% replied "no", and $14.9 \%$ replied "undecided". When participants were asked "What are the topics you feel insufficient about drugs?", $21.5 \%$ replied "drug indications", 58.6\% replied "drug doses", 43.1\% replied "drug contraindications", $47.9 \%$ replied "drug complications", and $7.7 \%$ replied "administration methods". When participants were asked "What are the topics you feel insufficient about interventional procedures?", 18.5\% replied "indications", 43.1\% replied "contraindications", and 60.4\% replied "complications" (Table 2).

The comparison of the scores of paramedic students' knowledge level on drugs and administration methods according to gender and the universities they are attending is given in Table 3.

The total mean score average of paramedic students indicating their knowledge level on drugs and administration methods 


\begin{tabular}{|c|c|c|c|c|c|c|}
\hline Questions & & Unive & ersity & & & \\
\hline \multirow{4}{*}{$\begin{array}{l}\text { Do you think } \\
\text { that your } \\
\text { knowledge } \\
\text { level on drugs } \\
\text { and drug } \\
\text { applications is } \\
\text { sufficient? }\end{array}$} & & 1DEU & $2 \mathrm{EU}$ & Зіંલ̧̧ & $\mathbf{n}$ & $\%$ \\
\hline & Yes & 21 & 25 & 33 & 79 & 47.3 \\
\hline & No & 10 & 5 & 5 & 20 & 11.9 \\
\hline & Undecided & 23 & 19 & 26 & 68 & 40.8 \\
\hline \multirow{3}{*}{$\begin{array}{l}\text { Do you think } \\
\text { that your } \\
\text { knowledge } \\
\text { level on } \\
\text { interventional } \\
\text { procedures is } \\
\text { sufficient? }\end{array}$} & Yes & 39 & 41 & 50 & 130 & 77.8 \\
\hline & No & 5 & 2 & 1 & 8 & 4.7 \\
\hline & Undecided & 10 & 6 & 13 & 29 & 17.3 \\
\hline \multirow{3}{*}{$\begin{array}{l}\text { Do you think } \\
\text { you should be } \\
\text { further trained } \\
\text { on drugs and } \\
\text { interventional } \\
\text { procedures? }\end{array}$} & Yes & 40 & 31 & 41 & 112 & 67.0 \\
\hline & No & 4 & 12 & 14 & 30 & 17.9 \\
\hline & Undecided & 10 & 6 & 9 & 25 & 14.9 \\
\hline \multirow{5}{*}{$\begin{array}{l}\text { What are the } \\
\text { topics you feel } \\
\text { insufficient } \\
\text { about drugs? }\end{array}$} & Drug indications & 18 & 6 & 12 & 36 & 21.5 \\
\hline & Drug doses & 37 & 31 & 30 & 98 & 58.6 \\
\hline & $\begin{array}{l}\text { Drug } \\
\text { contraindications }\end{array}$ & 26 & 19 & 27 & 72 & 43.1 \\
\hline & $\begin{array}{l}\text { Drug } \\
\text { complications }\end{array}$ & 26 & 19 & 35 & 80 & 47.9 \\
\hline & $\begin{array}{l}\text { Administration } \\
\text { methods }\end{array}$ & 4 & 2 & 7 & 13 & 7.7 \\
\hline \multirow{3}{*}{$\begin{array}{l}\text { What are the } \\
\text { topics you feel } \\
\text { insufficient } \\
\text { about } \\
\text { interventional } \\
\text { procedures? }\end{array}$} & Indications & 18 & 7 & 6 & 31 & 18.5 \\
\hline & Contraindications & 30 & 19 & 23 & 72 & 43.1 \\
\hline & Complications & 28 & 31 & 42 & 101 & 60.4 \\
\hline \multicolumn{2}{|l|}{ Total } & 54 & 49 & 64 & 167 & 100 \\
\hline
\end{tabular}

was 54.724. There was a significant difference between the knowledge level of paramedic students in terms of gender, indicated by their total scores $(p=0.001)$. There was no difference between paramedic students' knowledge level on drugs and administration methods in terms of the universities they attended $(p=0.470)$.

The comparison of paramedic students' knowledge level on interventional procedures according to gender and the universities they are attending is given in Table 4 .

The total mean score of paramedic students on interventional procedures knowledge level was 65.653. No difference was found in the knowledge level on interventional procedures between
Table 3. Comparison of drugs and administration methods knowledge level scores of the paramedics according to gender and universities

\begin{tabular}{|l|l|l|l|l|l|}
\hline \multicolumn{2}{|c|}{} & $\mathbf{n}$ & $\%$ & Mean score & p \\
\hline \multirow{3}{*}{ Gender } & Male & 80 & 47.9 & $52.011(10.412)$ & \multirow{2}{*}{0.001} \\
\cline { 2 - 5 } & Female & 87 & 52.1 & $57.675(10.974)$ & \\
\hline \multirow{3}{*}{ University } & 1DEU & 54 & 32.3 & $53.555(13.329)$ & \multirow{3}{*}{0.470} \\
\cline { 2 - 5 } & 2EU & 49 & 29.3 & $54.346(9.982)$ & \\
\cline { 2 - 5 } & 3íKÇU & 64 & 38.3 & $56.000(1.198)$ & \\
\hline
\end{tabular}

n: Number, DEU: Dokuz Eylül University, EU: Ege Universty, IKCU: İzmir Katip Çelebi Universty

Table 4. Comparison of interventional procedures knowledge level scores of the paramedics according to gender and universities

\begin{tabular}{|l|l|l|l|l|l|}
\hline \multicolumn{2}{|c|}{} & $\mathbf{n}$ & $\%$ & Mean score & $\mathbf{p}$ \\
\hline \multirow{4}{*}{ Gender } & Male & 80 & 47.9 & $65.675(14.774)$ & \multirow{3}{*}{0.985} \\
\cline { 2 - 6 } & Female & 87 & 52.1 & $65.632(14.044)$ & \\
\hline \multirow{3}{*}{ University } & 1DEU & 54 & 32.3 & $69.000(14.467)$ & \multirow{3}{*}{0.002} \\
\cline { 2 - 5 } & 2EU & 49 & 29.3 & $59.795(12.325)$ & \\
\cline { 2 - 5 } & 3IKCCU & 64 & 38.3 & $67.312(14.563)$ & \\
\hline
\end{tabular}

n: Number, DEU: Dokuz Eylül University, EU: Ege Universty, IKCU: Izmir Katip Çelebi Universty

the paramedic students in terms of gender $(p=0.985)$. However, a significant difference was found in the knowledge level on interventional procedures between the students studying at different universities $(p=0.002)$. Advanced analysis revealed that the difference was due to EU students $(p<0.019)(p<0.806$ for DEU and IKÇU).

\section{Discussion}

The aim of this study was to determine the knowledge level of paramedic (ambulance and emergency care technician) students studying at health services vocational schools of three universities on commonly used drugs and interventional procedures. Drugs and interventional procedures, which are an important part of treatment, are one of the main tasks of paramedics. Errors in drug administration and interventional procedures harm patients (11).

Our study was conducted with 167 paramedic senior students. Eighty-seven (52.1\%) of the participants were female and 80 (47.9\%) were male. $89.2 \%$ of the participants were between 19-21 years old. In the study of Işıklı (15), the majority of the participants were in the 16-33 age group (68.6\%). Similarly, in the study conducted by Haytaç (11), the majority of the participants were 18-26 years old (57\%), 152 (47.9\%) were female, and 162 
(52.1\%) were male. The older average age in these studies is thought to be due to the graduates included in the studies.

In our study, when we looked at the distribution of the answers given to the questions asked about paramedics' perceptions of their competence related to drugs and interventional procedures, we found that $47.3 \%$ of paramedic students answered "yes" to the question "Do you think that your knowledge level on drugs and drug applications is sufficient?". 77.8\% answered "yes" to the question "Do you think that your knowledge level on interventional procedures is sufficient?". 67\% answered "yes" to the question "Do you think you should receive further training on drugs and interventional procedures?". When asked about the topics they felt insufficient about drugs, 58.6\% of the participants answered "drug doses", 47.9\% answered "drug complications", $43.1 \%$ answered "drug contraindications", and only $7.7 \%$ answered "administration methods". When asked about the topics they felt insufficient about interventional procedures, the majority (60.4\%) answered "complications" (Table 2). Similar to our study, in the study of Haytaç (11), 41.1\% of paramedics answered "yes" to the question "Do you think that your knowledge level on drugs and drug applications is sufficient?", $66 \%$ answered "yes" to the question "Do you think that your knowledge level on interventional procedures is sufficient?", and $93.7 \%$ answered "yes" to the question "Do you think you should receive further training on drugs and interventional procedures?". Similarly, $44.3 \%$ of the participants answered "drug doses" to the question "What are the topics you feel insufficient about drugs? (You can select more than one option)" and 46.5\% answered "complications" to the question "What are the topics you feel insufficient about interventional procedures? (You can select more than one option)"

Allen et al. (16) found the drug error rate as 28.2\%. Eastwood et al. (17) suggested that paramedics had serious deficiencies in calculating the drug doses. Jacobsen et al. (18) found that most of the paramedics (98.9\%) recognized classic anaphylaxis but less than half (46.2\%) knew that epinephrine was the right drug, and made recommendations for increasing training. Kopp et al. (19) emphasized the lack of knowledge of drugs in their study. Walker et al. (20) found that the airway course increased paramedics' skills in airway maneuvers from $68 \%$ to $84 \%$. However, no difference was observed between achievement scores at 6 and 12 months. According to studies published in the literature, one of the most common problems in terms of patient safety is drug errors. In our study, one of the most common topics paramedics felt incompetent was drug doses (58.6\%) and complications of interventional procedures (60.4\%).

When we looked at the comparison of mean knowledge level scores of paramedic students on drug administration methods and interventional procedures according to gender and universities;
There was a significant difference between the mean knowledge level scores of paramedic students on drugs and administration methods in terms of gender $(p=0.001)$. There was no difference between paramedic students' knowledge level on interventional procedures in terms of gender $(p=0.985)$. In his study, Haytaç (11) found no statistical difference between mean scores in terms of gender (male: 72.29, female: 69.19) ( $p>0.005)$.

There was no difference in paramedic students' knowledge level on drugs and administration methods in terms of the universities they attended $(p=0.470)$. However, a significant difference was found in paramedic students' knowledge level on interventional procedures in terms of the universities they attended $(p=0.002)$. Advanced analysis revealed that the difference was due to EU students $(p<0.019)(p<0.806$ for DEU and IKÇU).

\section{Study Limitations}

The research was limited to the paramedic students of only three universities.

\section{Conclusion}

In the present study, 87 (52.1\%) of the paramedic students were female and 80 (47.9\%) were male. $89.2 \%$ of the participants were between 19-21 years old. When paramedic students were questioned about their perception of competence on drugs and interventional procedures, $52.7 \%$ of the paramedic students stated that their knowledge level on drugs and drug applications was not sufficient and $22.2 \%$ stated that their knowledge level on interventional procedures was not sufficient. $67.0 \%$ of the paramedic students stated that they think they should be further trained about drugs and interventional procedures.

The topics where paramedic students feel most incompetent about are drug doses (58.6\%) and complications of interventional procedures (60.4\%). Based on the answers given to the questions, the highest score obtained by the participants was 81.0 and the lowest score was 31.0.

The mean total score of paramedic students on their knowledge level of drugs and administration methods is 54.724. The total mean total score of paramedic students on their knowledge level of interventional procedures is 65.653 .

There was a significant difference between the knowledge level of paramedic students on drugs and administration methods in terms of gender $(p=0.001)$. No difference was found between the knowledge level of paramedic students on interventional procedures in terms of gender $(p=0.985)$.

There was no significant difference between the knowledge level of paramedic students on drugs and administration methods 
$(p=0.470)$. However, a significant difference was found between the knowledge level of paramedic students on interventional procedures according to the universities they attended ( $p=0.002$ ). Advanced analysis revealed that the difference was due to EU students $(p<0.019)(p<0.806$ for DEU and IKÇU).

It was determined that the low knowledge level of paramedic students on drug usage and interventional procedures. Appropriate guidelines and checklists, which consider the weaknesses of the given education and include the updates, should be prepared for paramedics working in emergency care to ensure standardization for safe drug administration and to reduce the complications of interventional procedures.

\section{Ethics}

Ethics Committee Approval: This study was approved by Dokuz Eylül University Noninvasive Researches Ethics Committee (no: 2019/09-49, date: 10.04.2019).

Informed Consent: Paramedic students were informed about the study and verbal consent was obtained from those who accepted to participate in the study.

Peer-review: Externally peer-reviewed.

\section{Authorship Contributions}

Concept: T.G., S.Y., Design: T.G., S.Y., Data Collection or Processing: T.G., S.Y., Analysis or Interpretation: T.G., S.Y., Literature Search: T.G., Writing: T.G., S.Y.

Conflict of Interest: No conflict of interest was declared by the authors.

Financial Disclosure: The authors declared that this study received no financial support.

\section{References}

1. Tabak RS, Som Yürek Hi. First Aid and Emergency Care Book for Nurses, 1st Edition, İstanbul: Palme Publications; 2007.

2. Çelikli S. Standardization efforts and breaking points in paramedic education since its establishment. Prehosp Journal. 2016;1:39-54.
3. Caroline NL. Emergency in the Streets. Massachusetts: Jones and Bartlett Publishers; 2007

4. Celikli S. Ambulance and emergency care technician (paramedic) program. International Participation III. Ambulance Rally and Emergency Health Services Congress. Ankara; 2007.p.33-7.

5. Ünlüoğlu İ, Ekși A, Anık N. A new health occupational group; Paramedics. J Contin Med Educ. 2002;11:308.

6. Sofuoğlu T, Vatansever K, Gezgin Y, Özgün S. Pre-hospital emergency care services. In: Uçan ES. Çelikli S. Üstünkarlı N. Ersoy G. Editors. Paramedic. First Edition, İzmir: Dokuz Eylül University Publication; 2000.p.139-50.

7. T.C. Ministry of Health. Implementing Regulation Amending the Regulation on Emergency Health Services, Number: 26463, March 15, 2007.

8. T.C. Ministry of Health. Communite on Procedures and Principles of Ambulance and Emergency Care Technicians and Emergency Medical Technicians. Number: 27181, 26 March 2009

9. Ozel G, Akbuga Ozel B, Ozcan C. First and emergency technician paramedic clinical issues, professional skills, operational practices book. Ed. Ozel G, 1st Edition. Ankara: Günes Medical Bookstores; 2016.

10. Ekși A, Ercal T, Celiklis, Ustunkarli N, Eroglu Aygul S, Aslan D. Pre-hospital emergency care, 1st Edition, İzmir: Kitapana; 2015.p.1-6.

11. Haytaç E. Determination of paramedics (ambulance and emergency care technician) knowledge about commonly used drugs and interventional procedures, Yıldırım Beyazıt University, Faculty of Medicine, Ankara: Master thesis; 2017

12. Sencan H. Reliability and validity of social and behavioral measurements. 1st Edition, Ankara: Seçkin Publishing; 2005.

13. Thomas JH, Moore M, Mindell JA. Controversies in behavioral treatment of 13 sleep problems in young children. Sleep Med Clin. 2014;9:251-9.

14. Sümbüloğlu K, Sümbüloğlu V. Biostatistics. 13th Edition, Ankara: Hatipoglu Publishing; 2009.

15. Ișıklı D. Evaluation of nursing knowledge of pharmacology (thesis). Konya: Selcuk University 2006

16. Allen T, Christlieb C, Gray SL, McCormick WC, Reinhard S, Sikma SK, et al. Types, Prevalence, and Potential Clinical Significance of Medication Administration Errors in Assisted Living. J Am Geriatr Soc. 2008;56:1199-205.

17. Eastwood KJ, Boyle MJ, Williams B. Paramedics' ability to perform drug calculations. West J Emerg Med. 2009;10:240-3.

18. Jacobsen RC, Toy S, Bonham AJ. Anaphylaxis knowledge among paramedics: results of a national survey. Prehosp Emerg Care. 2012;16:527-34.

19. Kopp BJ, Erstad BL, Allen ME, Theodorou AA, Priestley G. Medication errors and adverse drug events in an intensive care unit: direct observation approach for detection. Crit Care Med. 2006;34:415-25.

20. Walker M, Jensen JL, Leroux $\mathrm{Y}$. The impact of intense airway management training on paramedic knowledge and confidence measured before, immediately after and at 6 and 12 months after training. Emerg Med J. 2013;30:334-8. 